\section{S-107 UNION BURYING GROUND: MORTALITY, MORTALITY INEQUITIES, AND SINKING LABOR-UNION MEMBERSHIP IN THE UNITED STATES}

${ }^{1}$ Jerzy Eisenberg-Guyot, Anjum Hajat. ${ }^{1}$ Columbia University Mailman School of Public Health, United States

\subsection{6/OEM-2021-EPI.409}

Introduction Over the last several decades in the U.S., socioeconomic life-expectancy inequities have increased 1-2 years. Declining labor-union density has fueled growing income inequities across classes and exacerbated racial income inequities. However, the relationship between declining labor-union density and mortality inequities remains understudied.

Objectives Using Panel Study of Income Dynamics (PSID) data, we examined the longitudinal union-mortality relationship and estimated whether declining union density has exacerbated racial and educational mortality inequities.

Methods Our sample included respondents ages 25-66 to the 1979-2015 PSID with mortality follow-up through age 68 and year 2017. To address healthy-worker bias, we used the parametric g-formula. First, we estimated how a scenario setting all (versus none) of respondents' employed-person-years to union-member employed-person-years would have affected mortality incidence. Next, we examined gender, racial, and educational effect modification. Finally, we estimated how racial and educational mortality inequities would have changed if union-membership prevalence had remained at 1979 (versus 2015) levels throughout follow-up.

Results In the full sample (respondents=23,022, observations $=146,681$ ), the union scenario was associated with lower mortality incidence than the non-union scenario (RR: 0.90, 95\% CI: 0.80, 0.99; RD per 1,000: -18.7, 95\% CI: -36.5, $0.9)$. This protective association generally held across subgroups, although it was stronger among the more-educated. However, we found little evidence mortality inequities would have lessened if union membership had remained at 1979 levels.

Conclusion To our knowledge, this is the first individual-level U.S.-based study with repeated union-membership measurements to analyze the union-mortality relationship. We estimated a protective union-mortality association, but found little evidence declining union density has exacerbated mortality inequities, although we did not incorporate contextual-level effects.

\section{S-109 IDENTIFICATION OF CHEMICAL AND DISINFECTANTS PRODUCTS FOR EXPOSURE AND EPIDEMIOLOGICAL STUDIES}

${ }^{1}$ Homero Harari, Gladys Palaguachi, Isabel Cuervo, Deysi Flores, Gerald Mastroianni, Maria Baldwin, Sherry Baron. ${ }^{1}$ Mount Sinai School of Medicine, United States

\subsection{6/OEM-2021-EPI.410}

Objective There is a large number of household cleaning chemical products available in the market for consumers and domestic cleaners. Online catalogs of major US retailers showed that there are over 450 different household cleaning products for sale. The objective of this study was to identify the household chemical products available for domestic cleaners and consumers as part of a study aimed at studying exposure to cleaning chemicals in Latinx domestic cleaners in New York City.
Methods We organized focus groups and interviews to develop a survey for Latinx cleaners in NYC. The survey was used to collect detailed information about the most common household cleaning tasks and cleaning product use in 400 Latinx domestic cleaners. In addition, we visited 95 retail stores in Latinx dense neighborhood in NYC to identify the types of household cleaning products available for sale. Finally, we created an inventory of household cleaning products available in the market for consumers and domestic cleaners and reviewed Safety Data Sheets to identify common chemical ingredients reported by manufacturers.

Results Despite a large number of cleaning chemicals available in the US market, Latinx domestic cleaners use less than 50 products for household cleaning during their jobs. In visits to retail stores we found that over $25 \%$ of the household cleaning products available for sale contain disinfectants such as Quaternary Ammonium Compounds and that over 80\% of the products contain a scent.

Conclusion A combination of quantitative and qualitative methods allowed us to determine the most common products domestic Latinx cleaners use and can be exposed while at work. This information will be used in a study to measure inhalation and dermal exposures in domestic cleaning.

\section{S-135 APPLYING THE EXPOSOME CONCEPT TO WORKING-LIFE HEALTH: THE EU EPHOR PROJECT}

${ }^{1}$ Anjoeka Pronk, Miranda Loh, Eelco Kuijpers, Maria Albin, Jenny Selander, Lode Godderis, Manosii Ghosh, Roel Vermeulen, Susan Peters, Ingrid Sivesind Mehlum, Michelle Turner, Vivi Schlünssen, Marcel Goldberg, Manolis Kogevinas, Barbara Harding, Svetlana So. 'TNO, Netherlands

\subsection{6/OEM-2021-EPI.411}

Introduction Exposures at work have a major impact on noncommunicable diseases (NCDs). Current risk reduction policies and strategies are informed by existing scientific evidence, which is limited due to the challenges of studying the complex relationship between exposure in the work place and outside work, and health. We define the working-life exposome as all occupational and related non-occupational (i.e. urban, lifestyle, behavioural and socio economic status) exposures.

Objective By taking an exposome approach, the Exposome Project for Health and Occupational Research (2020-2024) aims to advance knowledge on the complex working life exposures in relation to disease beyond the single high exposure-single health outcome paradigm, mapping and relating interrelated exposures to inherent biological pathways, key body functions and health.

Methods This will be achieved by combining 1) large-scale harmonisation and pooling of existing cohorts systematically looking at multiple exposures and diseases, with 2) the collection of new high-resolution (in time or agents/markers) external and internal exposure data in two case studies. Methods and tools to characterize the working-life exposome will be developed and applied, including sensors, wearables, a harmonised job exposure matrix (EuroJEM), non-invasive biomonitoring, omics, data mining, and (bio)statistics.

Results\&Conclusion

The toolbox of developed methods and knowledge will be made available to policy makers, occupational health practitioners and scientists. Advanced knowledge on working life exposures in relation to NCDs will serve as a basis for 